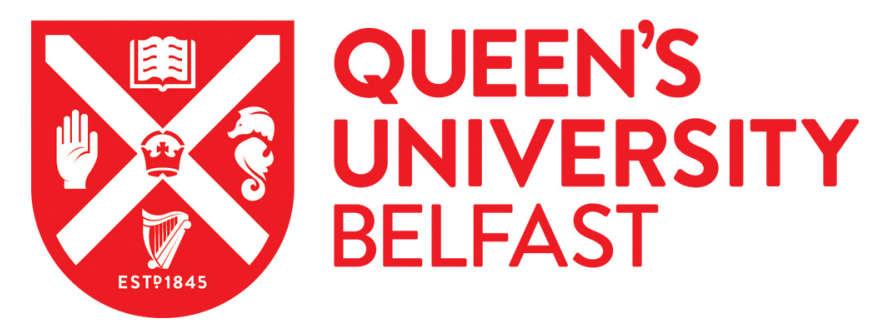

\title{
Stressor intensity determines antagonistic interactions between species invasion and multiple stressor effects on ecosystem functioning
}

Vye, S. R., Emmerson, M. C., Arenas, F., Dick, J. T. A., \& O'Connor, N. E. (2015). Stressor intensity determines antagonistic interactions between species invasion and multiple stressor effects on ecosystem functioning. Oikos, 124(8), 1005-1012. https://doi.org/10.1111/oik.01583

Published in:

Oikos

Document Version:

Peer reviewed version

Queen's University Belfast - Research Portal:

Link to publication record in Queen's University Belfast Research Portal

Publisher rights
(C) 2014 The authors

This is the accepted version of the following article: Stressor intensity determines antagonistic interactions between species invasion and multiple stressor effects on ecosystem functioning, which has been published in final form at http://onlinelibrary.wiley.com/doi/10.1111/oik.01583/full

The definitive version is available at www.onlinelibrary.wiley.com.

General rights

Copyright for the publications made accessible via the Queen's University Belfast Research Portal is retained by the author(s) and / or other copyright owners and it is a condition of accessing these publications that users recognise and abide by the legal requirements associated with these rights.

Take down policy

The Research Portal is Queen's institutional repository that provides access to Queen's research output. Every effort has been made to ensure that content in the Research Portal does not infringe any person's rights, or applicable UK laws. If you discover content in the Research Portal that you believe breaches copyright or violates any law, please contact openaccess@qub.ac.uk. 


\title{
0 Stressor intensity determines antagonistic interactions between species invasion and multiple stressor effects on ecosystem functioning
}

\author{
Siobhan R. Vye, Mark C. Emmerson, Francisco Arenas, Jaimie T. A. Dick and Nessa E. O'Connor
}

Biological invasions, nutrient enrichment and ocean warming are known to threaten biodiversity and ecosystem functioning. The independent effects of these ecological stressors are well studied, however, we lack understanding of their cumulative effects, which may be additive, antagonistic or synergistic. For example, the impacts of biological invasions are often determined by environmental context, which suggests that the effects of invasive species may vary with other stressors such as pollution or climate change. This study examined the effects of an invasive seaweed (Sargassum muticum) on the structure and functioning of a synthetic macroalgal assemblage and tested explicitly whether these effects varied with nutrient enrichment and ocean warming. Overall, the presence of $S$. muticum increased assemblage productivity rates and warming altered algal assemblage structure, which was characterised by a decrease in kelp and an increase in ephemeral green algae. The effects of $S$. muticum on total algal biomass accumulation, however, varied with nutrient enrichment and warming, producing antagonistic cumulative effects on total algal biomass accumulation. These findings show that the nature of stressor interactions may vary with stressor intensity and among response variables, which leads to less predictable consequences for the structure and functioning of communities.

There are persistent increases in the range and intensity of anthropogenic stressors exerted on the natural environment (Vitousek et al. 1997), despite efforts to mitigate these impacts through legislation such as the EU Habitats Directives (EU 1992) and the Australian Environment

[AQ1] Protection and Biodiversity Conservation Act 1999. Loss of

35 biodiversity is thought to be driven by ecological stressors such as habitat loss and fragmentation (Pimm and Raven 2000), species invasions (Simberloff et al. 2013), eutrophication (Smith et al. 1999), global warming (Schiel et al. 2004) or even ocean acidification (Kroeker et al. 2010). The individual impacts of such stressors on certain species or whole communities have been documented (reviewed by Kroeker et al. 2010 and Thomsen et al. 2011), however, multiple stressors often occur simultaneously (Crain et al. 2008). Multiple stressors may have simple additive effects on ecosystems, which could be predicted from previous studies of independent stressor effects (Kroeker et al. 2010, Dossena et al. 2012). Alternatively, stressors may interact with each other non-additively, leading to a cumulative impact that is either greater than (synergistic) or less than (antagonistic)

50 the sum of the independent effects (Crain et al. 2008). Results from recent meta-analyses suggest that non-additive

interactions are common and the nature of such interactions can vary with environmental context, such as habitat type or climatic conditions (Crain et al. 2008, Darling and Côté 2008). Currently, synergistic cumulative impacts are predicted to be most common, driven by the de-stabilizing effect of a primary stressor that reduces resistance of ecosystems to other stressors, thus, leading to 'ecological surprises' and potentially rapid declines in biodiversity and ecosystem functioning (Paine et al. 1998, Doak et al. 2008). Uncertainty surrounding the cumulative impacts of stressors and the context-dependency of potential interactions among two or more stressors demands more robust experimental work to disentangle such cumulative effects (Crain et al. 2008).

Coastal ecosystems are among the most economically valuable (Barbier et al. 2011) and heavily exploited (Lotze et al. 2006). Among the most ubiquitous stressors in coastal ecosystems are nutrient enrichment, the spread of invasive species and global warming (Lotze et al. 2006). Individually, these stressors can degrade habitats (Smith et al. 1999), change species distributions and assemblage structures (Dossena et al. 2012), and alter ecosystem processes (Thomsen et al. 2011). Non-additive interactions may occur where these stressors influence ecosystems simultaneously and lead to complex cumulative impacts (Mckee et al. 2002, 
$0 \quad$ Kratina et al. 2012). For example, nutrient enrichment may amplify an increase in productivity and growth rates induced by warming, by reducing the metabolic constraints associated with nutrient supply (Tadonléké 2010).

Previous research has focussed on interactions among nutrient enrichment, climate change and species loss (Blake and Duffy 2010, O'Connor and Donohue 2013), while interactions with another common biotic stressor, invasive species, have been less well studied (Strayer 2012). Impacts of invasive species, including the replacement of native species and alteration of ecosystem process rates, are often context-dependent (Thomsen et al. 2011), which may drive different responses between invaded and non-invaded communities to other stressors (Olabarria et al. 2013). Experimental manipulation is required to test how the

15 presence of an invasive species alters community responses to other stressors and to test clearly for potential additive, antagonistic or synergistic interactions among stressors. This study aimed to separate the cumulative effects of three common stressors on the structure and functioning of synthetic assemblages (Diaz et al. 2003) representative of a coastal ecosystem. We tested explicitly for non-additive cumulative effects of: 1) the presence of an invasive algal species (Sargassum muticum); 2) nutrient enrichment; and 3) ocean warming, on assemblage productivity, algal biomass accumulation and assemblage structure of a synthetic macroalgal assemblage.

\section{Methods}

This experiment ran for six weeks during June-July 2012 in outdoor flow-through mesocosms at Queen's Univ. Marine Laboratory, Portaferry, Co. Down, Northern Ireland. The mesocosm array consisted of ten sea water tables, each containing eleven 45-1 mesocosms supplied with sand filtered seawater direct from the adjacent Strangford Lough. Shallow coastal benthic assemblages were created to mimic rock pool communities on local shores, which are typical of the region and based on local field surveys. Synthetic assem-

40 blages comprised of six algal species (Fucus serratus, $21 \mathrm{~g}$ wet biomass; Laminaria digitata, $17 \mathrm{~g}$; Corallina officialis, $16 \mathrm{~g}$; Mastocarpus stellatus, 3 g; Cladophora sp., 2 g; Ulva lactuca, $1 \mathrm{~g}$ ), which were present in proportional abundance and biomass of each species in rock pools of similar size to the mesocosms. Algae were cleared of epiphytes manually and insecticide was used to remove unwanted epibiota. Algae were attached to plastic mesh $(20 \mathrm{~mm}$ mesh size) in each mesocosm and seawater was aerated and renewed by dump buckets (approx. mean flow-through rate: $41 \mathrm{~min}^{-1}$ ) simu-

50 lating wave action on rocky shores. Grazing gastropods were added to each mesocosm to incorporate a realistic grazing pressure on the algae based on surveys of the most abundant grazers in local rock pools. These were the limpet Patella vulgata (2.27 individuals $\left.\mathrm{m}^{-1}\right)$, winkle, Littorina littorea

55 (3.23 individuals $\left.\mathrm{m}^{-1}\right)$ and topshell, Gibbula umbilicalis (4.63 individuals $\mathrm{m}^{-1}$ ). Thus, typical grazing pressure was incorporated into the experimental design and each mesocosm had two limpets (dry biomass: $10.51 \pm 0.44 \mathrm{~g}$, mean \pm S.E.), three winkles $(7.53 \pm 0.15 \mathrm{~g})$ and four topshells $60 \quad(3.72 \pm 0.08 \mathrm{~g})$.

\section{Experimental design and set-up}

The three factors manipulated in the experiment were: 1 ) presence of an invasive species (Sargassum muticum; fixed, two levels: invaded, non-invaded); 2) nutrient concentration (fixed, three levels: ambient, $\mathrm{N}+, \mathrm{N}++$; and 3) water temperature (fixed, three levels: ambient, $\mathrm{T}+, \mathrm{T}++$ ), yielding eighteen experimental treatments and ninety experimental units ( $\mathrm{n}=5$, of all possible combinations). This factorial design allowed the independent and interactive effects of each of the stressors (all three factors at each level) to be tested. Treatments were allocated randomly to mesocosms, which were rearranged approximately weekly to minimise location artefacts (Bruno and O'Connor 2005).

The presence of an invasive species was manipulated by the addition of $S$. muticum $(11 \mathrm{~g})$. This fucoid algae, originating in northeast Asia, is invasive in northwest Europe and became established in Strangford Lough in 1995 (Boaden 1995). Sargassum muticum is a strong competitor with native species and a driver of community structural changes (White and Shurin 2011). In non-invaded treatments, S. muticum was substituted with the morphologically similar (Wernberg et al. 2000) native fucoid Halidrys siliquosa (11 g) to control for biomass addition, thus, all synthetic assemblages contained similar total algal biomass $(60 \mathrm{~g})$ at the beginning of the experiment.

In nutrient enriched treatments, the inorganic nitrogen and phosphorus content of the mesocosms was elevated using slow release fertilizer pellets $(11 \mathrm{~N}: 11 \mathrm{P}: 18 \mathrm{~K})$ contained in $50 \mathrm{ml}$ nutrient diffusers $(70 \mathrm{~g}$ in $\mathrm{N}+$ and $140 \mathrm{~g}$ in $\mathrm{N}++$ treatments) similar to Worm et al. (2000). Non-enriched treatments contained empty diffusers to limit experimental artefacts. To ensure that nutrient enrichment treatments were effective, water samples were taken after four weeks and analysed using an autoanalyzer. Water samples from enriched treatments had significantly greater concentrations of dissolved inorganic nitrogen (DIN), phosphorus and ammonium (Kruskal-Wallis test with multiple comparisons, ambient $<\mathrm{N}+<\mathrm{N}++$, DF $=2$, p $<0.001)$. Ambient nutrient enrichment treatments contained $1.63 \pm 0.07 \mu \mathrm{m}$ $1^{-1}$ DIN, $0.38 \pm 0.01 \mu \mathrm{m} \mathrm{l}^{-1}$ phosphate and $0.68 \pm 0.03$ $\mu \mathrm{m} \mathrm{l}^{-1}$ ammonium (mean $\pm \mathrm{SE}$ ), typical of low summer nutrient concentrations in this region (Hydes et al. 1999). Medium nutrient enrichment $(\mathrm{N}+)$ raised DIN content by $0.89 \pm 0.224 \mu \mathrm{m} \mathrm{l}^{-1}$, phosphate content by $0.191 \pm 0.018$ $\mu \mathrm{m} \mathrm{l}^{-1}$ and ammonium content by $0.533 \pm 0.044 \mu \mathrm{m} \mathrm{l}^{-1}$ above ambient, while high nutrient enrichment treatments $(\mathrm{N}++)$ elevated DIN by $1.112 \pm 0.112 \mu \mathrm{m} \mathrm{l}^{-1}$, phosphate content by $0.376 \pm 0.024 \mu \mathrm{m} \mathrm{l}^{-1}$ and ammonium content by $1.007 \pm 0.091 \mu \mathrm{m} \mathrm{l}^{-1}$ above ambient. This increase of around $70 \%$ is in line with previous nutrient enrichment studies (Worm et al. 2000, Sugden et al. 2008, CanningClode et al. 2008).

There were also three levels of seawater temperature in the experiment: ambient, medium $(\mathrm{T}+)$ and high $(\mathrm{T}++)$. Mesocosms were warmed as required using submersible aquarium heaters (300 watt). Water temperature was increased by $1.86 \pm 0.04^{\circ} \mathrm{C}(\mathrm{T}+$; mean $\pm \mathrm{SE})$ and $2.44 \pm 0.05^{\circ} \mathrm{C}$ $(\mathrm{T}++)$ above ambient temperature $\left(13.04 \pm 0.03^{\circ} \mathrm{C}\right)$ during the experiment, which mimics current climate change predictions for this region (IPCC 2007) and tracked 
0 natural variation. Water temperature within each mesocosm was monitored during the experiment and warming treatments were effective (mixed effects model, fixed factor: temperature treatment, random factor: mesocosm, with Tukey post hoc comparisons, ambient $<\mathrm{T}+<\mathrm{T}++$, $\mathrm{DF}=2, \mathrm{p}<0.001$, Supplementary material Appendix 1).

\section{Response variables}

Gross assemblage productivity was estimated from dissolved 10 oxygen concentrations using an optical probe after periods of artificially induced darkness and subsequent similar periods of sunlight (Nielsen 2001, Noël et al. 2010). Initial oxygen concentration was measured and then mesocosms were immediately covered with a lid and subject to a dark 15 incubation period of $90-120 \mathrm{~min}$ to estimate respiration. After incubations, a second set of measurements for oxygen concentration were taken. A third set of measurements were then taken after a further 20-70 min light period that allowed photosynthesis to resume. Dark incubation periods

20 were varied to ensure that a quantifiable change in dissolved oxygen concentration was achieved and light incubation periods were varied to avoid oxygen super-saturation (Noël et al. 2010). Gross assemblage productivity was calculated from the sum of estimates of net assemblage productivity 25 and assemblage respiration. Productivity measurements were standardised for algal dry biomass (Griffin et al. 2010). Photosynthetically active radiation (PAR) was recorded during oxygen concentration measurement and mean PAR was $1345.41 \pm 18.46 \mu \mathrm{E} \mathrm{s}^{-1} \mathrm{~m}^{-2}($ mean $\pm \mathrm{SE}, \mathrm{n}=270)$.

30 Irradiance levels were above those recorded as saturating light in similar rock pool assemblages $(600 \mu \mathrm{mol}$ photons $\mathrm{s}^{-1} \mathrm{~m}^{-2}$, Arenas et al. 2009).

Dry biomass (dried at $60^{\circ} \mathrm{C}$ until a constant biomass) of each algal species was quantified at the end of the experiment

35 to test for differences in algal assemblage structure and biomass accumulation among treatments. Total algal biomass accumulation was calculated as the sum of the difference between dry biomass at the beginning and the end of the experiment. Algal dry biomass at the start of the experiment

40 was derived from wet-dry biomass relationships established for all species through the collection and drying $\left(60^{\circ} \mathrm{C}\right.$ until a constant biomass) of additional wet biomass samples.

\section{Data analysis}

Three-way analysis of variance (ANOVA) was used to test for non-additive cumulative effects among treatments on gross assemblage productivity and total algal biomass accumulation. This approach was utilised as interaction terms within an ANOVA test for deviations from the additive model and allow antagonistic and synergistic interactions among stressors to be identified (Billick and Case 1994, Dunne 2010). To preserve the integrity of the experimental procedure, eighteen (out of ninety) experimental units were excluded

55 from the analysis because precise grazer densities could not be assured for the duration of the experiment. This led to some uneven replication of treatments, however, all treatments were replicated a minimum of three times. To account for unequal replication of some treatments, type III sum of the fixed factors invasion, nutrient enrichment and water temperature and included all possible interactions among these terms. Models were checked for homogeneity of variances using plots of standardised residuals versus fitted values as well as standardised residuals versus the explanatory variables used in each model and QQ-plots and histograms were used to test for normality in conjunction with ShapiroWilk and Levene's tests. Gross assemblage productivity was transformed (cube root) to meet assumptions of normality and heteroscedacity. Post hoc pairwise $t$-tests (Tukey HSD) were used to make comparisons among levels of significant terms. Data were visualised using means and error (95\% confidence intervals) plots to reflect the construct of the ANOVA and add clarification to the results, which is an accepted and informative approach to visualise results of multiple stressor studies ( Blake and Duffy 2012, O'Gorman et al. 2012, Burnell et al. 2013). Permutational multivariate analyses of variance (PERMANOVA; Anderson 2001) was used to test hypotheses involving algal assemblage structure, based on Bray-Curtis resemblance matrices calculated from algal dry biomass data with 9999 permutations of residuals under a reduced model. This permutation method was chosen because it reduces type I error for multifactorial analysis (Anderson et al. 2008). Algal dry biomass data were fourth root transformed for multivariate analysis to meet assumptions of homogeneity of dispersions and to reduce the influence of the most abundant species on assemblage structure (Clarke and Warwick 2001). The dry biomass of S. muticum and $H$. siliquosa were not included in this analysis to distinguish the responses of other species to the presence of $S$. muticum from the response of $S$. muticum itself. Where significant differences were detected, post hoc pairwise $t$-tests were used to make comparisons among levels of significant terms. Similarity of percentages (SIMPER) analyses were conducted to test for individual algal species contributions to overall differences in assemblage structure (Clarke and Warwick 2001). The magnitude of all treatment effects were obtained through the calculation of generalised omegasquared $\left(\omega^{2}\right)$ effect sizes (Olejnik and Algina 2003). Multivariate analyses were undertaken in PRIMER ver. 6 (Clarke and Gorley 2006) and univariate analyses were undertaken in $\mathrm{R}$ ver. 2.14.2 (R Development Core Team 2011.)

\section{Results}

The presence of Sargassum muticum increased gross assemblage productivity, however, the effect size was small (Table 1a, Fig. 1a). There were no effects of nutrient enrichment or warming and no interactive effects among any of the stressors on gross assemblage productivity (Table 1a, Fig. 1).The presence of the invasive alga $S$. muticum altered total algal biomass accumulation, however, this effect changed with nutrient concentration and temperature (Table 1b, Fig. 2). Post hoc tests showed that in the absence of $S$. muticum, total algal biomass accumulation was significantly lower in the medium nutrient treatment compared to ambient and high nutrient treatments (Fig. 2a). Whereas, when S. muticum was present there was no effect of nutrients on algal biomass accumulation (Fig. 2a). In addition, the response of algal biomass accumulation to increasing water temperature varied 
Table 1. Tests for the effects of the presence of an invasive species, nutrient enrichment and warming on assemblage responses: (a) ANOVA with type III sums of squares for effects of the treatments on gross assemblage productivity after six weeks; (b) ANOVA with type III sums of squares for effects of the treatments on total algal biomass accumulation after six weeks, and (c) PERMANOVA based on Bray-Curtis dissimilarity matrix calculated from algal dry biomasses (fourth root transformed to standardise individual species contributions) with 9999 permutations of residuals under a reduced model. Significant terms are highlighted in bold. $\omega^{2}$-values are generalised omega-squared effect sizes. Negative $\omega^{2}$ are shown as zeros.

\begin{tabular}{|c|c|c|c|c|c|c|c|c|c|c|c|c|c|}
\hline \multirow[b]{2}{*}{ Source } & \multirow[b]{2}{*}{ DF } & \multicolumn{4}{|c|}{$\begin{array}{l}\text { (a) Gross assemblage } \\
\text { productivity }\end{array}$} & \multicolumn{4}{|c|}{$\begin{array}{l}\text { (b) Total algal biomass } \\
\text { accumulation }\end{array}$} & \multicolumn{4}{|c|}{$\begin{array}{l}\text { (c) Algal assemblage } \\
\text { structure }\end{array}$} \\
\hline & & MS & $\mathrm{F}$ & $\mathrm{p}$ & $\omega^{2}$ & MS & $\mathrm{F}$ & $\mathrm{p}$ & $\omega^{2}$ & MS & $\mathrm{F}$ & $\mathrm{p}$ & $\omega^{2}$ \\
\hline Invasion (Inv) & 1 & 0.040 & 6.483 & 0.014 & 0.071 & 6.188 & 0.769 & 0.384 & 0.000 & 19.634 & 0.635 & 0.610 & 0.000 \\
\hline Nutrient enrichment (Nut) & 2 & 0.003 & 0.456 & 0.636 & 0.000 & 54.817 & 6.810 & 0.002 & 0.139 & 32.941 & 1.066 & 0.389 & 0.000 \\
\hline Temperature (Temp) & 2 & 0.002 & 0.391 & 0.678 & 0.000 & 25.022 & 3.109 & 0.053 & 0.055 & 77.081 & 2.494 & 0.029 & 0.039 \\
\hline Inv $\times$ Nut & 2 & 0.002 & 0.307 & 0.737 & 0.000 & 43.360 & 5.387 & 0.007 & 0.108 & 66.197 & 2.142 & 0.056 & 0.031 \\
\hline Inv $\times$ Temp & 2 & 0.001 & 0.146 & 0.865 & 0.000 & 26.178 & 3.252 & 0.046 & 0.058 & 15.114 & 0.489 & 0.811 & 0.000 \\
\hline Nut $\times$ Temp & 4 & 0.004 & 0.624 & 0.647 & 0.000 & 1.728 & 0.215 & 0.929 & 0.000 & 22.456 & 0.727 & 0.713 & 0.000 \\
\hline Inv $\times$ Temp $\times$ Nut & 4 & 0.008 & 1.316 & 0.276 & 0.017 & 4.393 & 0.546 & 0.702 & 0.000 & 8.677 & 0.281 & 0.983 & 0.000 \\
\hline Residuals & 54 & 0.006 & & & & 8.049 & & & & 30.907 & & & \\
\hline
\end{tabular}

between non-invaded and invaded assemblages, however, this effect was comparatively small compared to the interaction (Table 1b). In the absence of $S$. muticum, algal biomass reduced with warming of $2.4^{\circ} \mathrm{C}$ compared to ambient and medium temperature treatments (Fig. 2b). There was no effect of temperature on total algal biomass when $S$. muticum was present (Fig. 2b). As such, this invasive species appears to provide a form of resistance to the effects of nutrient enrichment and, to a far lesser extent, warming on total algal biomass accumulation. Increasing temperature affected algal assemblage structure (Table 1c). Specifically, assemblage structure differed in high warming treatments compared to both medium and ambient treatments $(\mathrm{T}++\neq \mathrm{A} ; \mathrm{t}=1.919, \mathrm{p}=0.045 ; \mathrm{T}++\neq$ $\mathrm{T}+\mathrm{t}=1.640, \mathrm{p}=0.047 ; \mathrm{A}=\mathrm{T}+\mathrm{t}=0.489, \mathrm{p}=0.873$, nMDS: Supplementary material Appendix 2). This shift in
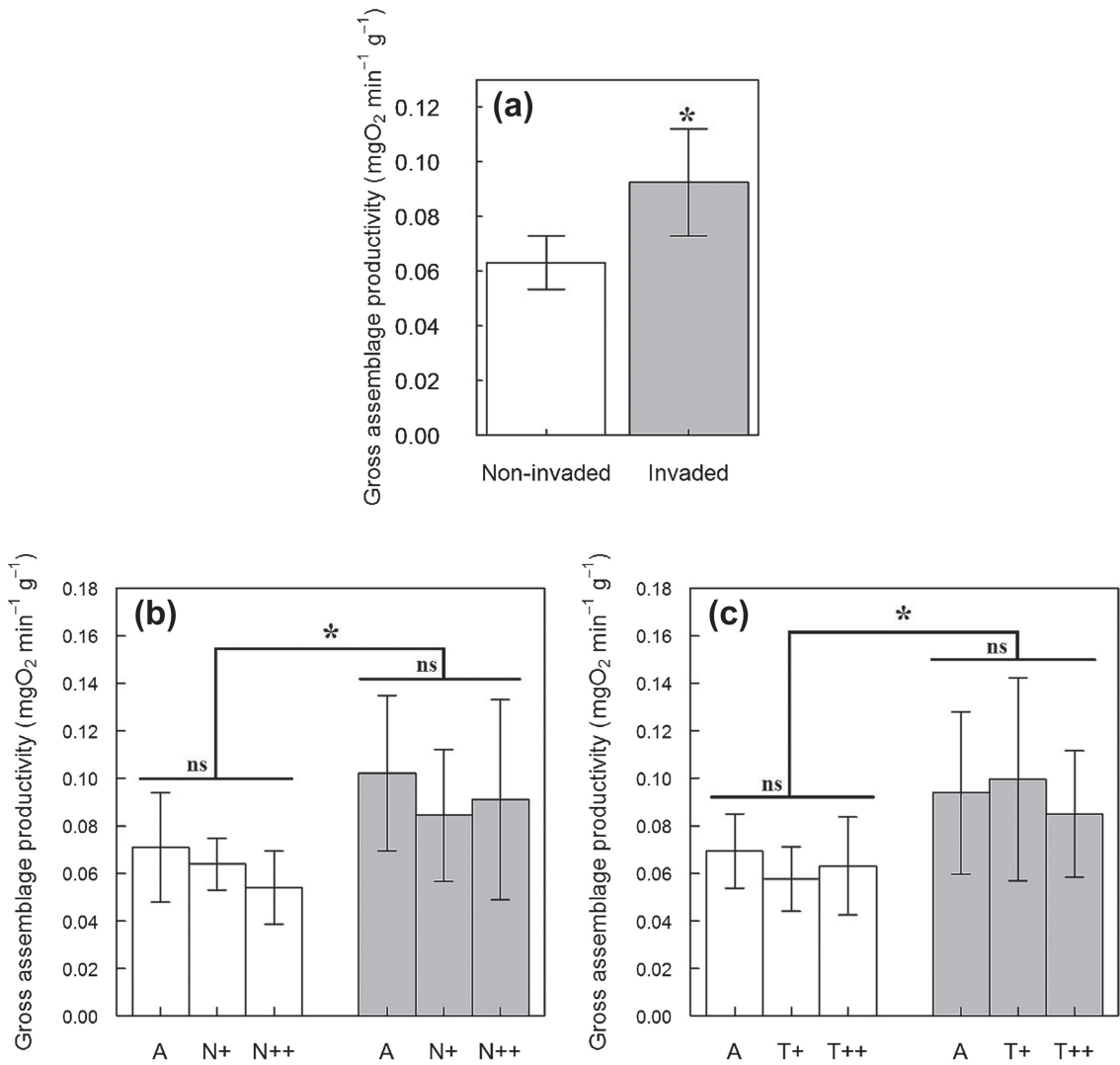

Figure 1. Means $( \pm 95 \%$ confidence interval) of gross assemblage productivity in experimental treatments following the construct of comparisons within the three factor ANOVA. (a) Gross assemblage productivity in all treatments with the presence and absence of Sargassum muticum (analysis is based on 33 invaded and 39 non-invaded replicates as temperature and nutrient enrichment treatments were pooled); (b) Gross assemblage productivity in each of the nutrient enrichment treatments (each bar represents between $\mathrm{n}=11$ and $\mathrm{n}=14$ replicates as temperature treatments were pooled); (c) Gross assemblage productivity in each of the temperature treatments (each bar represents between $n=10$ and $n=14$ as nutrient enrichment treatments were pooled). Non-invaded treatments are denoted by open 


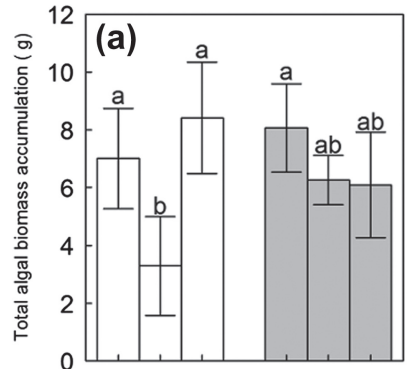

A $\mathrm{N}+\mathrm{N}++\quad$ A $\mathrm{N}+\mathrm{N}++$

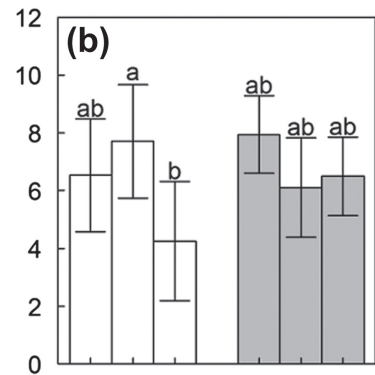

A $\mathrm{T}+\mathrm{T}++\quad$ A $\mathrm{T}+\mathrm{T}++$
Figure 2. Means ( $\pm 95 \%$ confidence interval) of total algal biomass accumulation in treatments following the construct of comparisons within the three factor ANOVA. Total algal biomass accumulation in (a) each nutrient enrichment treatment (each bar represents between $n=11$ and $n=14$ replicates as temperature treatments were pooled) and (b) each temperature treatment (each bar represents between $n=10$ and $n=14$ replicates as nutrient enrichment treatments were pooled). Non-invaded treatments are denoted by open bars and invaded treatments are denoted by grey bars. Letters indicate treatments that are statistically indistinguishable from each other based on post hoc tests $(\mathrm{p}>0.05)$.

algal assemblage structure was driven generally by an increase in the green alga, Ulva lactuca (Fig. 3f) and reduction in biomass of the brown alga Laminaria digitata (Fig. 3b) in warmer treatments compared to cooler treatments (Table 2). None of the other species showed strong responses to warming (Fig. 3a, c-e). There were no effects of species invasion or nutrients on algal assemblage structure (Table 1c).

\section{Discussion}

By manipulating the presence of an invasive species (Sargassum muticum), nutrient enrichment and warming simultaneously, we have shown that, although the impact of invasion can be independent (e.g. assemblage productivity), the response of the invaded community to other stressors can also differ from non-invaded communities (e.g. algal biomass accumulation). Our findings illustrate the nonadditive cumulative effects of multiple stressors. However,
Table 2. SIMPER analysis identifying algal species that contributed to dissimilarities in assemblage structure in response to warming treatments including comparisons between: (a) ambient conditions and medium warming (mean dissimilarity $=6.31 \%$ ); (b) medium and high warming (mean dissimilarity $=7.31 \%$ ); and (c) mean dissimilarity between ambient and $\mathrm{T}++=7.83 \%$.

\begin{tabular}{|c|c|c|c|c|}
\hline Species & Mean bi & nass (g) & Diss/SD & Contribution (\%) \\
\hline (a) & A & $\mathrm{T}+$ & & \\
\hline Ulva lactuca & 0.153 & 0.290 & 1.24 & 42.31 \\
\hline Corallina officialis & 6.787 & 6.558 & 1.18 & 15.09 \\
\hline Cladophora sp. & 0.800 & 0.786 & 0.67 & 14.14 \\
\hline Laminaria digitata & 5.911 & 6.068 & 1.34 & 12.85 \\
\hline Fucus serratus & 8.582 & 9.000 & 1.36 & 8.44 \\
\hline Mastocarpus stellatus & 1.456 & 1.518 & 1.36 & 7.17 \\
\hline (b) & $\mathrm{T}+$ & $\mathrm{T}++$ & & \\
\hline Ulva lactuca & 0.290 & 0.323 & 1.23 & 35.04 \\
\hline Laminaria digitata & 6.068 & 3.867 & 0.94 & 28.95 \\
\hline Corallina officialis & 6.558 & 6.372 & 1.07 & 13.36 \\
\hline Cladophora sp. & 0.786 & 0.846 & 1.29 & 9.18 \\
\hline Mastocarpus stellatus & 1.518 & 1.647 & 1.34 & 6.90 \\
\hline Fucus serratus & 9.000 & 8.591 & 1.00 & 6.57 \\
\hline (c) & A & $\mathrm{T}++$ & & \\
\hline Ulva lactuca & 0.153 & 0.323 & 1.24 & 33.99 \\
\hline Laminaria digitata & 5.911 & 3.867 & 0.88 & 25.80 \\
\hline Corallina officialis & 6.787 & 6.372 & 1.16 & 13.19 \\
\hline Cladophora sp. & 0.800 & 0.846 & 0.72 & 12.74 \\
\hline Fucus serratus & 8.582 & 8.591 & 1.16 & 7.39 \\
\hline Mastocarpus stellatus & 1.456 & 1.647 & 1.37 & 6.89 \\
\hline
\end{tabular}

interactions were only present for one of the processes quantified in the experiment and, importantly, these effects were determined by stressor intensity.

The presence of $S$. muticum led to a small, but statistically significant, increase in gross assemblage productivity, thus, providing support for the theory that invasive species can have wider ranging impacts beyond effects on single species (Simberloff et al. 2013). The mechanism behind this increased productivity in invaded assemblages may be associated with differences in the functional traits, such as phenology and growth rates, of $S$. muticum compared to the morphologically similar native species, Halidrys siliquosa. Although both species are considered perennial, the phenology of $S$. muticum and $H$. siliquosa differ (Wernberg et al.
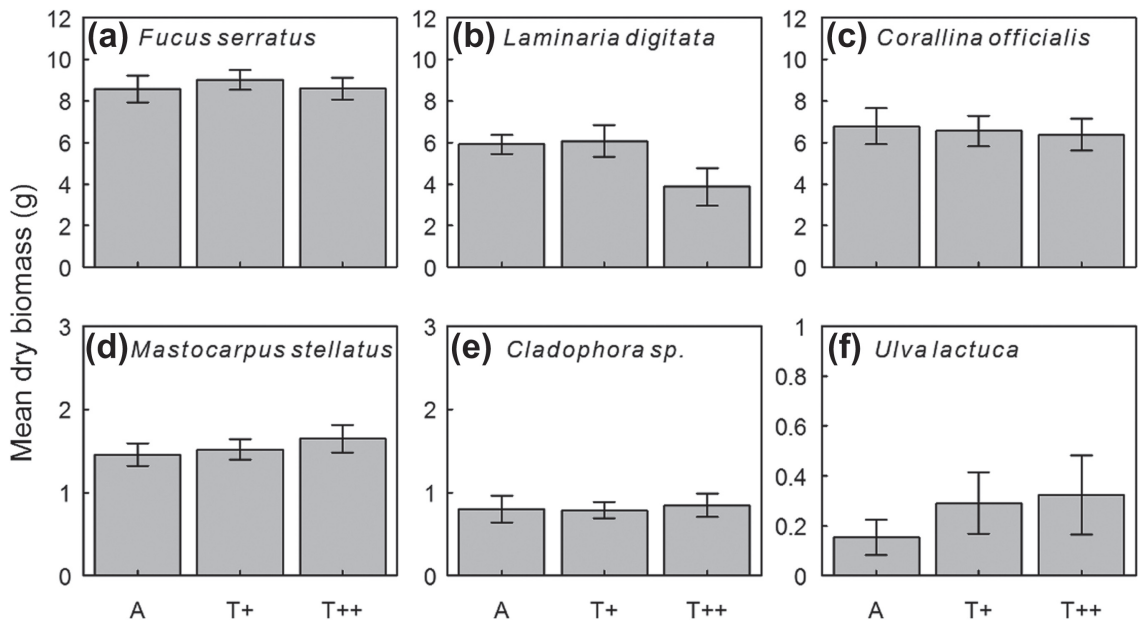

Figure 3. Means $( \pm 95 \%$ confidence interval) of algal species dry biomass after six weeks in each of the temperature treatments $(A: n=22$,

$\mathrm{T}+: \mathrm{n}=24, \mathrm{~T}++: \mathrm{n}=26$ as nutrient enrichment and invasion treatments were pooled). 
0 2000). This experiment was conducted in summer when northeast Atlantic populations of $S$. muticum undergo a rapid growth phase, whereas $H$. siliquosa does not show any seasonal variation in growth (Wernberg et al. 2000). The rapid seasonal growth rate of $S$. muticum is thought to be supported by increased rates of photosysnthesis rather than by the use of stored carbon, suggesting that higher photosynthetic rates may occur in this period when compared to winter months (Lewey and Gorham 1984). This rapid growth can cause $S$. muticum to dominate algal assemblages,

10 constraining light avaliability, which may reduce other species photosynthetic ability and lead to declines in the abundance of underlying algae (White and Shurin 2011). Interestingly, in this study the presence of $S$. muticum did not alter assemblage structure suggesting that this process did not occur and indicating that although $S$. muticum increased rates of productivity, this was not to the detriment of other species. It is possible that the lack of a dominance effect on assemblage structure may be because of the short duration of the study, or owing to differences in limiting resources

20 between natural and mesocosm systems (Stachowicz et al. 2008).

We did not detect any effects of warming or nutrient enrichment on assemblage productivity rates, however, warming altered assemblage structure through increases in biomass of the ephemeral green alga, Ulva lactuca and declines in the biomass of the brown alga, Laminaria digitata in treatments with a warming of $2.4^{\circ} \mathrm{C}$. Although statistically the effect size was small, this change in assemblage structure is of notable ecological interest owing to the importance of $L$. digitata for the functioning of coastal ecosystems. Laminaria digitata is a kelp species that thrives in colder waters and is thought to be near the southern limit of its geographical range on these shores (Smale et al. 2013). Kelp is a highly productive component of coastal ecosystems, supporting diverse communities and facilitating the provision of many coastal goods and services (Smale et al. 2013). Our findings support concerns that global warming may threaten kelp species, which are at the edge of their range, potentially causing range contraction 40 and declines in associated ecosystem services (Smale et al. 2013). There was no reduction in assemblage productivity associated with the decline in biomass of $L$. digitata under warmed conditions, indicating that the corresponding increase in $U$. lactuca may have compensated in terms of maintaining assemblage productivity. Ephemeral algae, such as U. lactuca, have previously been shown to proliferate in increased warming scenarios (Schiel et al. 2004). Although $L$. digitata and $U$. lactuca are not functionally equivalent (Littler 1980), increases in U. lactuca biomass and productivity may have compensated for the decline of L. digitata and therefore account for the lack of an effect of warming on overall assemblage productivity. A similar compensation effect has been identified from recent field experiments where the proliferation of ephemeral species maintained community productivity after the loss of canopy species (Crowe et al. 2013). It has been shown that shifts in algal assemblage structure can maintain processes such as total biomass and production at similar rates, however, different algal species are rarely functionally true compensation cannot be infered (Bruno et al. 2005, O'Connor and Bruno 2007).

In terms of the cumulative effects of stressors, we identified non-additive interactive effects on total algal biomass accumulation, however, contrary to previous work (Staehr and Sand-Jensen 2006), we found no evidence of an interaction between nutrient enrichment and warming on assemblage productivity. Nutrient enrichment could be expected to enhance the effects of warming on assemblage productivity through reduction of potential nutrient limitation (Staehr and Sand-Jensen 2006). However, our results suggest that nutrient supply may not be a limiting factor in this system, because there were no effects of nutrient enrichment on productivity rates or assemblage structure.

We have demonstrated how the effect of a stressor (e.g. nutrient enrichment) on total algal biomass accumulation was determined by the presence of a second stressor (e.g. an invasive species). For example, the decrease in algal biomass accumulation in medium nutrient enriched treatments seen in non-invaded assemblages, did not occur when the second stressor, the invasive species $S$. muticum, was present. This suggests that an antagonistic interaction occured between these stressors. Antagonistic interactions have been identified between other pairs of anthropogenic stressors, such as between nutrient enrichment and ocean acidification (Burnell et al. 2013). In our study, total algal biomass accumulation was similar across treatments when S. muticum was present, whereas in non-invaded assemblages under medium nutrient enrichment and under high warming treatments there was a decline in algal biomass accumulation. The antagonistic interaction between the presence of S. muticum and warming effects on algal biomass accumulation may have been driven by differences in the reponses of $H$. siliquosa and $S$. muticum to warming. In non-invaded assemblages, $H$. siliquosa may have a reduced fitness in high warming treatments as water temperatures in these treatments were at the upper limits experienced typically by this species during the summer and, thus, could have led to a decrease in algal biomass accumulation in the non-invaded assemblages (Morris and Taylor 1983). In contrast, the positive effect of $S$. muticum on total algal biomass accumulation suggests that $S$. muticum is better adapted to take advantage of warmer water temperatures (Walther et al. 2009). Invasive species may have different tolerances to environmental variables, such as temperature, as a consequence of their different evolutionary environments (Byers et al. 2002). This rationale could explain why invasive species are sometimes better adapted to survive and respond successfully to opportunities driven by anthropogenic environmental change, such as increased resource avaliability from declines in native species (MacDougall and Turkingham 2005).

We have shown that in non-invaded assemblages, total algal biomass accumulation declined in medium nutrient enrichment treatments. The mechanism behind this non-additive effect is unclear, however, it is typical of the type of unpredictable results found when multiple stressors occur (Paine et al. 1998). One speculative explanation is that nutrient enrichment may have stimulated algal growth and increased levels of nitrogen in algal tissues through the storage of excess nutrients (Pedersen and Borum 1996). This could have provided a higher quality food source for grazing 
0 gastropods and enhanced grazing activity, which may have constrained algal biomass accumualation (Boyer et al. 2004). At the high levels of enrichment, algal growth may have been enhanced to a point where the bottom-up effects of nutrient enrichment were greater than the top-down grazing effects leading to greater biomass accumulation than in medium nutrient enrichment treatments. Although this explanation is speculative because specific grazing rates (top-down control) was not quantified as part of this study, direct and indirect effects of different levels of nutrient enrichment may

10 be a contributing factor to the differences in the importance of bottom-up and top-down control on algal growth and biomass as found in previous studies (Valdivia et al. 2008, Atalah and Crowe 2010). The current study is one of the few that has manipulated nutrient enrichment over more 5 than two levels (but see Sugden et al. 2008, Canning-Clode et al. 2008). Many previous studies crossing a wide range of systems have tested for a presence or absence effect of nutrient enrichment (Blake and Duffy 2010, O'Connor and Donohue 2013). These studies have allowed generalisations

20 to be formed (Smith et al. 1999, Sala and Knowlton 2006), however, there is no consideration of stressor effects occuring along an intensity gradient. Our study tested a range of nutrient enrichment and warming scenarios and highlights that there are more than simple presence or absence effect of stressors, which further complicates the prediction of interactive cumulative effects (Steudel et al. 2012).

The presence of antagonistic cumulative effects of multiple stressors on total algal biomass accumulation, but not on other assemblage responses (i.e. productivity), further highlights the unpredictable effects of multiple stressors on ecosystem functioning. Our findings provide strong empirical evidence of non-additive interactions among stressors, which is consistent with conclusions of recent meta analyses, indicating that antagonistic (Crain et al. 2008, Darling and Côté

35 2008), rather than synergistic cumulative effects are most prevalent (Sala and Knowlton 2006, Halpern et al. 2007). These non-additive interactions between the presence of the invasive species and other stressors exemplify how invasive species have a high potential for complex interactions owing to their context-dependent effects on biodiversity and ecosystem functioning (Thomsen et al. 2011, Simberloff et al. 2013).

To conclude, the presence of an invasive species affected functioning through both independent effects and nonadditive interactive effects with other stressors. In this study, non-additive interactive effects were determined by stressor intensity and varied depending on the ecosystem process. The unpredictable nature of these interactions highlights the importance of considering a range of ecosystem processes and more importantly, gradients of environmental contexts or stressor intensities when aiming to identify, predict and mitigate the wider impact of multiple stressors on ecosystem functioning and services.

Acknowledgements - We thank Brian Stewart of the Agri-Food and Biosciences Institute for nutrient analysis, Paula Curran and the staff of the QUB Marine Laboratory at Portaferry for assistance with the experiment and QUB Ecology Journal Club for comments on this manuscript. The manuscript was also greatly improved by the insightful comments of Dr Jarett Byrnes. This study was completed as part of a PhD funded by the Dept of Employment and Learning Northern Ireland.

\section{References}

Anderson, M. J. 2001. A new method for non-parametric multivariate analysis of variance. - Austral Ecol. 26: 32-46.

Anderson, M. J. et al. 2008. PERMANOVA+ for PRIMER: guide to software and statistical methods. - PRIMER-E.

Arenas, F. et al. 2009. Diversity effects beyond species richness: evidence from intertidal macroalgal assemblages. - Mar. Ecol. Prog. Ser. 381: 99-108.

Atalah, J. and Crowe, T. P. 2010. Combined effects of nutrient enrichment, sedimentation and grazer loss on rock pool assemblages. - J. Exp. Mar. Bio. Ecol. 388: 51-57.

Barbier, E. B. et al. 2011. The value of estuarine and coastal ecosystem services. - Ecol. Monogr. 81: 169-193.

Billick, I. and Case, T. J. 1994. Higher-order interactions in ecological communities - what are they and how can they be detected. - Ecology 75: 1529-1543.

Blake, R. E. and Duffy, J. E. 2010. Grazer diversity affects resistance to multiple stressors in an experimental seagrass ecosystem. - Oikos 119: 1625-1635.

Blake, R. and Duffy, J. 2012. Changes in biodiversity and environmental stressors influence community structure of an experimental eelgrass Zostera marina system. - Mar. Ecol. Prog. Ser. 470: 41-54.

Boaden, P. 1995. The adventive seaweed Sargassum muticum (Yendo) Fensholt in Strangford Lough, Northern Ireland. - Irish Nat. J. 25: 111-113.

Boyer, K. E. et al. 2004. Elevated nutrient content of tropical macroalgae increases rates of herbivory in coral, seagrass and mangrove habitats. - Coral Reefs 23: 530-538.

Bruno, J. F. and O'Connor, M. I. 2005. Cascading effects of predator diversity and omnivory in a marine food web. - Ecol. Lett. 8: 1048-1056.

Bruno, J. F. et al. 2005. Effects of macroalgal species identity and richness on primary production in benthic marine communities. - Ecol. Lett. 8: 1165-74.

Burnell, O. et al. 2013. Eutrophication offsets increased sea urchin grazing on seagrass caused by ocean warming and acidification. - Mar. Ecol. Prog. Ser. 485: 37-46.

Byers, J. E. et al. 2002. Impact of non-indigenous species on natives enhanced by anthropogenic alteration of selection regimes. - Oikos 97: 449-458.

Canning-Clode, J. et al. 2008. Influence of disturbance and nutrient enrichment on early successional fouling communities in an oligotrophic marine system. - Mar. Ecol. 29: 115-124.

Clarke, K. and Warwick, R. 2001. Changes in marine communities: an approach to statistical analysis and interpretation. - PRIMER-E.

Clarke, K. and Gorley, R. 2006. PRIMER v6: user maunal/tutorial. - PRIMER-E.

Crain, C. M. et al. 2008. Interactive and cumulative effects of multiple human stressors in marine systems. - Ecol. Lett. 11: 1304-1315.

Crowe, T. P. et al. 2013. Large-scale variation in combined impacts of canopy loss and disturbance on community structure and ecosystem functioning. - PLoS ONE 8: e66238.

Darling, E. S. and Côté, I. M. 2008. Quantifying the evidence for ecological synergies. - Ecol. Lett. 11: 1278-86.

Diaz, S. et al. 2003. Functional diversity revealed by removal experiments. - Trends Ecol. Evol. 18: 140-146.

Doak, D. F. et al. 2008. Understanding and predicting ecological dynamics: are major surprises inevitable? - Ecology 89: 952-961.
61 
0 Dossena, M. et al. 2012. Warming alters community size structure and ecosystem functioning. - Proc. R. Soc. B 279: 3011-3019.

Dunne, R. P. 2010. Synergy or antagonism - interactions between stressors on coral reefs. - Coral Reefs 29: 145-152.

EU 1992. Council Directive 92/43/EEC of 21 May 1992 on the conservation of natural habiatas and of wild fauna and flora.

Griffin, J. et al. 2010. Consumer effects on ecosystem functioning in rock pools: roles of species richness and composition. - Mar. Ecol. Prog. Ser. 420: 45-56.

Halpern, B. S. et al. 2007. Evaluating and ranking the vulnerability of global marine ecosystems to anthropogenic threats. - Conserv. Biol. 21: 1301-1315.

Hydes, D. et al. 1999. The balance of supply of nutrients and demands of biological production and denitrification in a temperate latitude shelf sea - a treatment of the southern North Sea as an extended estuary. - Mar. Chem. 68: 117-131.

IPCC 2007. Climate change 2007: synthesis report. Contrib. Working Groups I, II and III to the 4th Assess. Rep. of the Intergovernmental Panel on Climate Change (Pachauri, R. K. and Reisinger, A. eds). - IPCC.

Kratina, P. et al. 2012. Warming modifies trophic cascades and eutrophication in experimental freshwater communities. - Ecology 93: 1421-1430.

Kroeker, K. J. et al. 2010. Meta-analysis reveals negative yet variable effects of ocean acidification on marine organisms. - Ecol. Lett. 13: 1419-1434.

Lewey, S. A. and Gorham, J. 1984. Pigment composition and photosynthesis in Sargassum muticum. - Mar. Biol. 80: 109-115.

Littler, M. 1980. Morphological form and photosynthetic performances of marine macroalgae: tests of a functional/form hypothesis. - Bot. Mar. 22: 161-165.

Lotze, H. K. et al. 2006. Depletion, degradation, and recovery potential of estuaries and coastal seas. - Science 312: 1806-1809.

30 MacDougall, A. and Turkingham, R. 2005. Are invasive species the drivers or passengers of change in degraded ecosystems? - Ecology 86: 42-55.

Mckee, D. et al. 2002. Effects of simulated climate warming on macrophytes in freshwater microcosm communities. - Aquat. Bot. 74: 71-83.

Morris, S. and Taylor, A. C. 1983. Diurnal and seasonal variation in physico-chemical conditions within intertidal rock pools. - Estuar. Coast. Shelf Sci. 17: 339-355.

Nielsen, K. J. 2001. Bottom-up and top-down forces in tide pools: test of a food chain model in an intertidal community. - Ecol. Monogr. 71: 187-217.

Noël, L. M.-L. J. et al. 2010. Assessment of a field incubation method estimating primary productivity in rockpool communities. - Estuar. Coast. Shelf Sci. 88: 153-159.

O'Connor, N. E. and Bruno, J. F. 2007. Predatory fish loss affects the structure and functioning of a model marine food web. - Oikos 116: 2027-2038.

O'Connor, N. E. and Donohue, I. 2013. Environmental context determines multi-trophic effects of consumer species loss. - Global Change Biol. 19: 431-440.

O'Gorman, E. J. et al. 2012. Multiple anthropogenic stressors and the structural properties of food webs. - Science 93: 441-448.

Olabarria, C. et al. 2013. Response of macroalgal assemblages from rockpools to climate change: effects of persistent increase in temperature and $\mathrm{CO}_{2}$. - Oikos 122: 1065-1079.

Olejnik, S. and Algina, J. 2003. Generalized eta and omega squared statistics: measures of effect size for some common research designs. - Psychol. Meth. 8: 434-447.
Paine, R. T. et al. 1998. Compounded perturbations yield ecological surprises. - Ecosystems 1: 535-545.

Pedersen, M. and Borum, J. 1996. Nutrient control of algal growth in estuarine waters. Nutrient limitation and the importance of nitrogen requirements and nitrogen storage among phytoplankton and species of macroalgae. - Mar. Ecol. Prog. Ser. 142: 261-272.

Pimm, S. L. and Raven, P. 2000. Extinction by numbers. - Nature 403: 843-845.

R Development Core Team 2011. R: a language and environment for statistical computing (RDC Team, eds). - R Found. Stat. Comput. 1: 409.

Sala, E. and Knowlton, N. 2006. Global marine biodiversity trends. - Annu. Rev. Environ. Resour. 31: 93-122.

Schiel, D. R. et al. 2004. Ten years of induced ocean warming causes comprehensive changes in marine benthic communities. - Ecology 85: 1833-1839.

Simberloff, D. et al. 2013. Impacts of biological invasions: what's what and the way forward. - Trends Ecol. Evol. 28 58-66.

Smale, D. A. et al. 2013. Threats and knowledge gaps for ecosystem services provided by kelp forests: a northeast Atlantic perspective. - Ecol. Evol. 3: 4016-4038.

Smith, V. H. et al. 1999. Eutrophication: impacts of excess nutrient inputs on freshwater, marine, and terrestrial ecosystems. - Environ. Pollut. 100: 179-96.

Stachowicz, J. J. et al. 2008. Complementarity in marine biodiversity manipulations: reconciling divergent evidence from field and mesocosm experiments. - Proc. Natl Acad. Sci. USA 105: 18842-18847.

Staehr, P. A. and Sand-Jensen, K. 2006. Seasonal changes in temperature and nutrient control of photosynthesis, respiration and growth of natural phytoplankton communities. - Freshwater Biol. 51: 249-262.

Steudel, B. et al. 2012. Biodiversity effects on ecosystem functioning change along environmental stress gradients. - Ecol. Lett. 15: $1397-1405$.

Strayer, D. L. 2012. Eight questions about invasions and ecosystem functioning. - Ecol. Lett. 15: 1199-1210.

Sugden, H. et al. 2008. The interaction between nutrient availability and disturbance frequency on the diversity of benthic marine communities on the north-east coast of England. - J. Anim. Ecol. 77: 24-31.

Tadonléké, R. 2010. Evidence of warming effects on phytoplankton productivity rates and their dependence on eutrophication status. - Limnol. Oceanogr. 55: 973-982.

Thomsen, M. S. et al. 2011. A framework to study the contextdependent impacts of marine invasions. - J. Exp. Mar. Bio. Ecol. 400: 322-327.

Valdivia, N. et al. 2008. Disturbance mediates the effects of nutrients on developing assemblages of epibiota. - Austral Ecol. 33: 951-962.

Vitousek, P. M. et al. 1997. Human domination of Earth's ecosystems. - Science 277: 494-499.

Walther, G.-R. R. et al. 2009. Alien species in a warmer world: risks and opportunities. - Trends Ecol. Evol. 24: 686-693.

Wernberg, T. et al. 2000. Comparative phenology of Sargassum muticum and Halidrys siliquosa (Phaeophyceae : Fucales ) in Limfjorden, Denmark. - Bot. Mar. 43: 31-39.

White, L. F. and Shurin, J. B. 2011. Density dependent effects of an exotic marine macroalga on native community diversity. $-\mathrm{J}$. Exp. Mar. Bio. Ecol. 405: 111-119.

Worm, B. et al. 2000. In situ nutrient enrichment: methods for marine benthic ecology. - Int. Rev. Hydrobiol. 85: 359-375. 